\title{
La filosofía de la Revolución francesa en un curso de Luis Juan Guerrero de 1939*
}

Ricardo Ibarlucía*

Resumen: El presente artículo aborda un capítulo olvidado de la filosofía argentina del siglo veinte. Su tema principal es un curso sobre la filosofía de la Revolución francesa impartido por Luis Juan Guerrero (1899-1957) en el Colegio Libre de Estudios Superiores de Buenos Aires en 1939. Tomando como punto de partida los programas de los cursos que Guerrero dictó como Profesor de Ética en la Universidad de Buenos Aires durante la década de 1930, el trabajo reconstruye en detalle su argumento sobre la oposición entre la conciencia histórica y la conciencia revolucionaria inherente al pensamiento filosófico del siglo XVIII y proporciona relevante información sobre el contexto y las fuentes filosóficas, históricas y sociológicas que discute.

Palabras clave: Luis Juan Guerrero, Revolución francesa, Iluminismo, Conciencia histórica, Conciencia revolucionaria.

Abstract: This paper deals with a forgotten chapter of the Twentieth-century Argentine Philosophy. The main subject is a lecture-course on the Philosophy of the French Revolution delivered by Luis Juan Guerrero (1899-1957) at the Colegio Libre de Estudios Superiores of Buenos Aires in 1939. By taking as a point of

\footnotetext{
* Este texto forma parte de un trabajo más amplio sobre la trayectoria filosófica de Luis Juan Guerrero de la Universidad Nacional de San Martín y la École des Hautes Études en Sciences Sociales, desarrollado en el marco del proyecto UNSAM/Instituto de Investigaciones sobre el Patrimonio Cultural, 2012-2104 (MOO5) "Historia de las ideas estéticas en la Argentina: de la Revolución de Mayo al Bicentenario", con el auspicio del proyecto WORLDBRIDGES: Philosophy of History and Globalisation of Knowledge. Cultural Bridges Between Europe and Latin America (F7-PEOPLE-2013-IRSES: 612644).

${ }^{* *}$ Doctor y Licenciado en Filosofía. Investigador Principal del Centro de Investigaciones Filosóficas. Profesor Titular de Estética y Problemas de Estética contemporánea en la Universidad Nacional de San Martín, donde dirige el programa de Historia de las ideas estéticas argentinas del Instituto de Investigaciones sobre el Patrimonio Cultural. Está a cargo de la edición de las obras de Luis Juan Guerrero. Dirección electrónica: ribarlucia@gmail.com
} 
departure the syllabi of the courses that Guerrero gave as Professor of Ethics at the University of Buenos Aires during the 1930s, it reconstructs in detail his argument on the opposition between historical consciousness and revolutionary consciousness inherent to the philosophical thought of the eighteenth century. It also provides relevant background and contextual information about Guerrero's philosophical, historical and sociological sources.

Keywords: Luis Juan Guerrero, French Revolution, Enlightenment, Historical Consciousness, Revolutionary Consciousness.

En septiembre 1930, al producirse el golpe militar de José Félix Uriburu, Luis Juan Guerrero fue destituido de sus funciones como Delegado Interventor en la Facultad de Ciencias Económicas y Educacionales de la Universidad Nacional del Litoral y separado de su cargo de Profesor Titular de Estética en la Facultad de Humanidades de la Universidad Nacional de La Plata. Temiendo mayores represalias a causa de su pasado anarquista, ${ }^{1}$ se marchó a Europa y a su regreso, alrededor de un año y medio más tarde, se sumó a las actividades del Colegio Libre de Estudios Superiores (CLES), fundado en Buenos Aires por Roberto Giusti, Carlos Ibarguren, Alejandro Korn, Narciso Laclau, Aníbal Ponce y Luis Ressig como polo alternativo al "espíritu profesional" predominante en la enseñanza universitaria oficial. ${ }^{2}$

En 1932, brindó allí un primer "curso de especialización” de nueve clases sobre "Historia de la formación estética", al que siguió, en 1933, otro de doce clases sobre "Estética del Iluminismo".3

En 1936, habiendo recuperado su cátedra en la UNLP y asumido como Profesor Titular de Ética y Director del Instituto de Filosofía de la Facultad de Filosofía y Letras de la Universidad de Buenos Aires, Guerrero

\footnotetext{
${ }^{1}$ Sobre la actividad de Guerrero, entre 1920 y 1926, como miembro de la Liga de Educación Racionalista y la Editorial Argonauta, donde publicó textos de Rudolf Rocker, Errico Malatesta, Luigi Fabbri y Piotr Kropotkin, entre otros, véase nuestro trabajo "Luis Juan Guerrero, el filósofo ignorado", en Guerrero, Estética operatoria en sus tres direcciones, estudio preliminar, apéndice bibliográfico y edición al cuidado de Ricardo Ibarlucía: I. Revelación y acogimiento de la obra de arte. Estética de las manifestaciones artísticas, Buenos Aires, Universidad Nacional de San Martín, Biblioteca Nacional de la República Argentina, Las Cuarenta, 2009, [pp. 9-93] pp. 12-18.

${ }^{2}$ Colegio Libre de Estudios Superiores, Quince años de labor, 1930-1945, Buenos Aires, Talleres Gráficos de E. Bustos, 1946, p. 3.

${ }^{3}$ Ibid., p. 46.
} 
dictó dos cursos más en la sede del CLES, en la Avenida Santa Fe 1145. El primero, "Renovación de la filosofía actual sobre la base del problema del trabajo", se compuso de ocho clases y, sobre la base de las lecturas de Guerrero, puede inferirse que abordó, además del concepto de trabajo en Hegel y Marx, los desarrollos más recientes de Felix Krüger, Bernhard Groethuysen y Karl Löwith. ${ }^{4}$ El segundo, "Soledad y comunidad como raíces de la filosofía de nuestro tiempo", de seis clases, trató la misma problemática del programa "Direcciones de la ética social en la filosofía alemana contemporánea", que Guerrero impartió ese año en la UBA. ${ }^{5}$ Este programa se dividía en seis unidades: I. Ética de la "coexistencia" (la importancia de Johann Gottlieb Fichte y Ludwig Feuerbach en la "renovación del problema del tû"; la "proyección sentimental" y la teoría de Max Scheler de la "comprensión del prójimo"; la "radicalización del problema de la coexistencia" en Martin Heidegger; "el sujeto de la existencia cotidiana"; "el individuo en el papel del hombre social" según Karl Löwith; el "horizonte ontológico y ético para la interpretación de la noción de coexistencia"); II. Ética de la "comunidad" (la filosofía romántica, la sociología de Ferdinand Tönnies y el "dualismo de comunidad y sociedad"; la "Ética de la comunidad" de Max Scheler y Othmar Spann; crítica de la noción de Gemeinschaft); III. Ética del "Espiritu Objetivo" (la teoría hegeliana y las lecturas de Wilhelm Dilthey, Hans Freyer y Nicolai Hartmann; los "problemas de la Ética” del Objek-

${ }^{4}$ Ibid. Se ha conservado de este curso una fotografía reproducida en la revista Foro y Notariado de Bahía Blanca en 1957, con ocasión del fallecimiento de Guerrero (Archivo General de la Nación, Departamento de Documentos Fotográficos, $n^{\circ}$ 107324). Cfr. Felix Krüger, "Die Arbeit des Menschen als philosophisches Problem" y Bernhard Groethuysen, "Die Idee der Arbeit in der bürgerlichen Welt und Lebensanschauung", Blätter für Deutsche Philosophie. Zeitschrift der Deutschen Philosophischen Gesellschaft, hrsg. von Hugo Fischer, Bd. 3, 1929-30; Karl Löwith,"Max Weber und Karl Marx" y Herbert, Marcuse, "Über die philosophischen Grundlagen des wirtschaftswissenschaftlichen Arbeitsbegriffs", respectivamente en Archiv für Sozialwissenschaft und Sozialpolitik, Bd. 67, H. 1/2, 1932 y Bd. 69, H. 3, 1933. Guerrero cita otro trabajo de Marcuse en su programa de Ética de 1934: Hegels Ontologie und die Grundlegung einer Theorie der Geschichtlichkeit, Frankfurt am Main, Felix Meiner, 1932. Al respecto, véase Guerrero, "Ética: curso complementario (a cargo del profesor adjunto)", PCUBA, 1934, p. 141.

${ }^{5}$ Ibid. y Cursos y Conferencias. Revista del Colegio Libre de Estudios Superiores, año V, vol. X, nº7, Buenos Aires, agosto 1936, p. 782. 
tiver Geist y el "horizonte ontológico y ético" para su interpretación); IV. Ética de la "bistoricidad" (las "influencias divergentes" de Hegel y Jacob Burckhardt; Dilthey, Paul Yorck von Wartenburg y el examen de los conceptos de "temporalidad" e "historicidad" en Sein und Zeit, seguidos de una crítica de "su significado ético"); V. Ética de la "voluntad social" (las polémicas sobre "sociología del saber"; la teoría de las "ideologías" de Karl Mannheim; la "sociología existencialista" de Hans Freyer como "Ética de la voluntad social" y el "sociologismo ético"); VI. Ética de la "acción política" (el "existencialismo político" de Carl Schmitt, las posturas de Freyer y Alfred Bäumler y una crítica del "activismo" ético-político). ${ }^{6}$

${ }^{6}$ Guerrero, "Ética. Direcciones de la ética social en la filosofía alemana contemporánea", Universidad de Buenos Aires, Programas de los cursos, Buenos Aires, Imprenta y Casa Editora "Coni" [en adelante: PCUBA], 1936, pp. 49-54. Una amplia bibliografía, que comprendía sólo títulos en castellano, francés, italiano e inglés "al alcance de los alumnos", consignaba como fuentes: Hans Freyer, "Los sistemas de la historia universal"; Revista de Occidente, Madrid, no 99, 1931; Karl Jaspers, Ambiente espiritual de nuestro tiempo, trad. de Ramón de la Serna, Barcelona, Labor, 1933; Martin Heidegger, “¿Qué es metafísica?”, Sur, n5, Buenos Aires, 1932 (trad. de Raimundo Lida) y Cruzy Raya, nº, Madrid, 1933 (trad. de Xavier Zubiri); Carl Schmitt, "El proceso de la neutralización de la cultura", Revista de occidente, Madrid, no 80, 1930; Othmar Spann, Filosofía de la sociedad, Madrid, Revista de Occidente, 1933; Oswald Spengler, El hombre y la técnica: contribución a una filosofía de la vida, Madrid, Espasa-Calpe, 1932 y Años decisivos, Madrid, Espasa-Calpe, 1934; Spranger, Formas de vida. Psicología y ética de la personalidad, trad. de Ramón de la Serna, Madrid, 1935. Entre los estudios críticos se mencionaban: Carlos Astrada: El juego existencial, Buenos Aires, Babel, 1933, Idealismo metafísico y metafísica existencial, Buenos Aires, Universidad de Buenos Aires, Facultad de Filosofía y Letras, Instituto de Filosofía, 1936, "Max Scheler y el problema de una Antropología filosófica", Revista de la Universidad de Córdoba, año XVI, n 1/2, marzo-abril de 1929, "Vida y espíritu de la Metafísica scheleriana”, Sur, n4, Buenos aires, 1931 y "Heidegger y Marx", Cursos y Conferencias, vol. II, n 10, abril de 1933; Ernesto Grassi, "Il problema de la metafísica immanante di M. Heidegger", Giornale critico della filosofía italiana, Milano-Roma, tomo 11, n4, 1930; Emmanuel Lévinas, "Heidegger et l’Ontologie (Revue philosophique de la France, París, mai-juin 1933; Francisco Romero, "Guillermo Dilthey”, Humanidades, XXII, 1930; Jean-Wahl, "Heidegger et Kierkegaard”, Recherches philosophiques, Paris, $\mathrm{n}^{\circ} 2,1932$ y "Le problème de choix, l'existence et la transcendance dans la philosophie de Jaspers", Revue de Métaphysique et de Morale, n 41, 3, 1934. 
En 1938, Guerrero dictó en el CLES el curso "Panorama de las relaciones entre la teoría y la práctica en la historia del pensamiento filosófico", compuesto de seis clases. ${ }^{7} \mathrm{Al}$ año siguiente, su interés se focalizó en la filosofía de la historia. En "Interpretación histórica de la vida humana" - o "Actualidad de la filosofía de la historia", como también se anunció este curso de seis clases en la revista Cursos y conferencias- ${ }^{8}$ se ocupó aparentemente de temas similares a los del programa "Problemas éticos de la filosofía de la historia" de la UBA. Este último programa se dividía en tres grandes unidades: A) Formación de la conciencia histórica, abarcando el siglo XVIII y el Romanticismo; B) Estructuras de la Historia, que comprendía, por un lado, "Las objetivaciones espirituales y los peligros del extrañamiento objetivo" y, por el otro, "El dinamismo histórico" y sus interpretaciones; C) Sentido de la Historia, que articulaba cuatro puntos: "La tesis de la historicidad de la existencia humana", "La Historia como actividad y el problema de la libertad humana", "La historia como pensamiento y los problemas de la Filosofía de la Historia" y, por último, "Eticidad e Historia en Hegel". La bibliografía incluía obras de la Escuela de Marburgo (Ernst Cassirer), el neo-idealismo (Benedetto Croce, Giovanni Gentile, Guido de Ruggero, R. G. Collingwood), la axiología (Max Scheler), el existencialismo cristiano (Nikolai Berdiaeff, Arnold Dempf, Paul Tillich, Étienne Gilson), la Leipziger Schule (Hans Freyer), la sociología formal (Alfred Vierkandt), el círculo parisino de Alexandre Kojève y la Escuela de Frankfurt (Raymond Aron, Éric Weil), así como del Warburg Institut (Raymond Klibansky, Herbert J. Paton, Erwin Panofsky, Fritz Saxl), la moderna historia cultural de Johan Huizinga, la historia de las mentalidades (Groethuysen), la mitología de las sociedades primitivas (Lucien Lévy-Brhul), la historia de la filosofía (Émile Bréhier) y las tesis de José Ortega y Gasset sobre "historiología". ${ }^{10}$

\footnotetext{
${ }^{7}$ Colegio Libre de Estudios Superiores, Quince años de labor, p. 46.

${ }^{8}$ Ibid. y Cursos y Conferencias, año VIII, vol. XV, n¹-2, Buenos Aires, abril-mayo de 1939, p. 196.

${ }^{9}$ Guerrero, "Ética. Tema: Problemas éticos de la Filosofía de la Historia", PCUBA, 1939, p. 47.

${ }^{10}$ Ibid., pp. 48-49. Entre las obras citadas, cabe destacar: Raymond Aron, Essai sur la théorie de l' Histoire dans l' Allemagne contemporaine, Paris, Alcan, 1933 e Introduction à la Philosophie de l'Histoire. Essai sur les limites de l'objectivité historique, Paris, Gallimard, 1937; Nicolás Berdiaeff, El sentido de la Historia, Barcelona, Araluce, 1936), Ernst Cassirer, La filosofia dell Illuminismo, Firenze, La Nuova Italia, 1936; R. G.
} 
En julio de 1939, Guerrero participó del primer "curso colectivo" del CLES, en el que intervinieron también Simón M. Neuschlosz, Ricardo Caillet Bois, José Luis Romero, Luis Roque Gondra, Julio V. González, Émile Gouiran, Jorge Romero Brest, Ariel Maudet, Julio E. Payró, Enrique Gallo, Erwin Leuchter, Patrick O. Dudgeon, Alberto Palcos, Emilio Ravignani, Juan C. Vedoya, Juan E. Cassani y Julio Caillet-Bois. ${ }^{11}$ Dedicado a la Revolución francesa, este ciclo de treinta y tres clases tenía el firme propósito de contrarrestar el silencio que las autoridades nacionales habían impuesto en todas las universidades a la conmemoración del sesquicentenario. Sin embargo, cuando la revista Cursos y Conferencias publicó, en 1940, dos gruesos volúmenes con las exposiciones, el estallido de la Segunda Guerra Mundial y la rápida capitulación de Francia arrojaban su sombra sobre este documento de la intelectualidad argentina que se reconocía en los ideales de libertad, igualdad y fraternidad de 1789. " "La burguesía francesa, otrora tan erguida sobre viejas conquistas, está muda -escribía Reissig en el prefacio-. Sus trofeos y sus mitos, sus instituciones y sus dogmas, se archivan. ¿Qué es de aquella burguesía pujante que supo movilizar millones

Collingwood, Human Nature and Human History, London, H. Milford, 1936; Benedetto Croce, Teoria e storia della Storiografía, Bari, Laterza, 1938 y La storia come pensiero e come azione, Laterza, Bari 1938; Hans Freyer, "Los sistemas de la historia universal", Revista de Occidente, no 99, 1933; Giovanni Gentile, "Introduzione a una nuova filosofia della storia", Giornale critico della filosofia italiana, Anno 18, n², 3 y 4, 1937; Johan Huizinga, Sobre el estado actual de la ciencia histórica: cuatro conferencias, trad. de María de Meyere, Madrid, Revista de Occidente, 1934; Raymond Klibansky \& H. J. Paton, Warburg Institute (eds.), Philosopby and History. Essays presented to Ernst Cassirer [con ensayos de E. Panofsky y F. Saxl], Oxford, The Clarendon Press, 1936; José Ortega y Gasset, "La Filosofía de la Historia de Hegel y la Historiología", Revista de Occidente, n 66, 1928 y "Guillermo Dilthey y la idea de la vida", Revista de Occidente, $\mathrm{n}^{\circ}$ 125, 126 y 127, 1933-1934; Richard Peters, La estructura de la Historia Universal en Juan Bautista Vico, Madrid, Revista de Occidente, 1930; Max Scheler, "Idea del hombre y la historia", Revista de Occidente, no 41, 1926 y Sociología del saber, Madrid, Revista de Occidente, 1935; Paul Tillich, The Interpretation of History, New York/London, Charles Scribner's Son, 1936; Alfredo Vierkandt, Filosofía de la sociedad y de la historia, La Plata, Universidad Nacional de La Plata, 1934; Eric Weil, "De l'interét que l'on prend à l'histoire", Recherches philosophiques, IV, 1934-1935.

${ }^{11}$ Colegio Libre de Estudios Superiores, Quince años de labor, p. 12.

${ }^{12}$ Cursos y Conferencias, 2 tomos: La Revolución francesa I, año IX, vol. XVI, n 2-3, Buenos Aires, mayo-junio 1940; La Revolución francesa II, n²4-5, julio-agosto 1940. 
de hombres en el 89 y que recogió los abultados frutos de la primera gran revolución?"13

Guerrero tuvo a su cargo el curso inaugural, titulado "La conciencia histórica en el siglo XVIII” y compuesto de dos clases. La versión taquigráfica se reprodujo, con algunas modificaciones y ampliaciones, en el primer tomo de la edición especial de Cursos y conferencias sobre la Revolución Francesa, distribuida en cuatro capítulos: "I. La conciencia histórica en el plano de la filosofía iluminista"; "II. La conciencia histórica en el plano de la existencia burguesa"; "III. Las antinomias de la conciencia histórica"; "La conciencia revolucionaria de 1789 y su herencia en los movimientos sociales del siglo XIX". ${ }^{14}$ Su papel en el marco del ciclo dedicado a la Revolución francesa, advierte Guerrero en la introducción, es el tratamiento de un problema filosófico concreto: "dilucidar si la voluntad revolucionaria de los hombres de 1789 proviene de la concepción de la vida histórica forjada por los pensadores de esa época o si, por el contrario, la niega o la transforma". ${ }^{15}$ Lejos de querer plantear, como lo han hecho tantos autores, desde Hippolyte Taine hasta Daniel Mornet, el conocido problema de la "influencias intelectuales" en la Revolución, su propósito es examinar "las relaciones entre conciencia histórica y la conciencia histórica" del Siglo de las Luces. ${ }^{16}$

Dicho de otra manera, su intención es considerar la conciencia revolucionaria del Iluminismo "en sus relaciones de continuidad y de antagonismo a la vez, y casi podríamos decir en sus relaciones dialécticas", con la conciencia histórica de la época. ${ }^{17}$ Con este fin, tratará la cuestión "en dos planos diferentes": primero, "en el proscenio de las controversias filosóficas del siglo, es decir, en el ámbito de las luces intelectuales que caracterizó al movimiento iluminista y que se tradujo (...) en la constitución de la Filosofía de la Historia"; luego, descendiendo "al plano más profundo

\footnotetext{
${ }^{13}$ Luis Reissig, "Prefacio", Cursos y Conferencias: La Revolución francesa I, [pp. 12651266] p. 1265.

${ }^{14}$ Guerrero, "La conciencia histórica en el siglo XVIII", Cursos y Conferencias, La Revolución francesa I, pp. 1267-1303.

${ }^{15}$ Ibid., p. 1267.

${ }^{16}$ Ibid., p. 1268. Guerrero alude a Hippolyte Taine, Les origines de la France contemporaine, 5 Tomes, Paris, Hachette, 1875-1893, particularmente los tomos II, III y IV, consagrados a la Revolución, y Daniel Mornet, Les origines intellectuelles de la Révolution française, Paris, Librairie Armand Colin, 1933.

${ }^{17}$ Ibid., p. 1268.
} 
de las convicciones y creencias de los hombres de la época" para rastrear "las intuiciones pre-filosóficas fundamentales" sobre las que se modeló "la imagen del hombre, la sociedad y la historia" propias del Tercer Estado. ${ }^{18}$ Sin pretender remontarse hasta las fuentes más profundas de estas creencias colectivas, la exposición no será más que "un fantasmagoría de ideas", justificable porque los hombres de esta época "presentaban precisamente sus problemas más vitales de una manera fantasmagórica: como ideas desprendidas de la humilde vida que las nutría". ${ }^{19}$ Como ha observado Hegel en sus Lecciones de Filosofía de la Historia, recuerda Guerrero, "toda la especulación del siglo XVIII obedeció a las leyes de la razón” y la misma Revolución francesa tuvo "en el pensamiento su comienzo y su fin”: “(...) por primera vez, el hombre penetró en la historia, consciente de su condición bumana, queriendo amoldar el curso de las cosas a los 'principios' que regían en el mundo de sus propias ideas". ${ }^{20}$

La filosofía francesa del siglo XVIII ha sido "racionalista" en un sentido radical, sostiene Guerrero en el comienzo de la primera parte, retomando una tesis del filósofo italiano Antonello Gerbi. ${ }^{21}$ Este racionalismo, cada vez más alejado de sus orígenes cartesianos y de las derivaciones jesuitas y jansenistas del siglo precedente, pasa de ser geométrico y metafísico a científico y experimental sobre todo en su asimilación del Iluminismo inglés. Así, se transforma paulatinamente en "un método, una actitud mental, una postura del hombre frente al mundo y la vida", que podría sintetizarse "en una fórmula fácil pero engañosa: racionalizar el mundo". ${ }^{22}$ Junto con los progresos científicos, esta filosofía alienta "los planes polí-

${ }^{18}$ Ibid.

${ }^{19}$ Ibid., pp. 1268-1269.

${ }^{20}$ Ibid., p. 1269. Cfr. Georg Wilhelm Friedrich Hegel, Vorlesungen über die Philosophie der Geschichte, hrsg. von Georg Lasson, Unveränderter Nachdruck der Ausgabe Berlin 1919 mit erneut ergänzten Literaturhinweisen, Hamburg, Felix Meiner [Philosophiseche Bibliotek], 1988, Band II-IV: Dritter Abschnitt. Die Dritte Periode: Die neue Zeit: 3. Die französische Revolution und ihre Folgen, p. 920. Guerrero cita por la traducción de José Gaos: Lecciones sobre Filosofía de la Historia universal, prólogo de José Ortega y Gasset, 2 tomos, Madrid, Revista de Occidente (Biblioteca de Historiología), 1928, t. 2, Capítulo III: La Edad Moderna, p. 399.

${ }^{21}$ Ibid., p. 1269-1270. Cfr. Antonello Gerbi, La politica del Settecento. Storia di un'idea, Bari, Laterza, 1928.

${ }^{22}$ Ibid., p. 1270. 
ticos, las utopías sociales, los esquemas de la historia, las explicaciones de la vida natural y salvaje a través de los libros de viaje, los análisis de las costumbres en los más diversos pueblos y otras múltiples preocupaciones humanas, exclusivamente humanas." ${ }^{33}$ Su ideal filosófico es "la felicidad del hombre", pero este ideal "ya no está la beatitud eterna, como en la visión cristiana, sino en la felicidad terrena de la vida", como una meta asequible por medio del bienestar material, la libertad política, la conquista de una mejor posición social, la educación y la salud corporal. ${ }^{24}$

Esto es lo que hace del Iluminismo, "más que un movimiento teórico, un movimiento esencialmente práctico (...) que pone a la ciencia y el saber en general al servicio de ciertas aspiraciones culturales, políticas y sociales". ${ }^{25}$ Coincidiendo en este punto con Ernst Cassirer, para quien el concepto de razón iluminista se define como "el concepto no de un ser sino de un hacer", según leemos en su obra sobre la Aufklärung, citada en italiano en la bibliografía del curso de Ética dictado en la UBA en 1939, ${ }^{26}$ Guerrero argumenta que la filosofía francesa del siglo XVIII "se vuelve cada vez más radicalmente práctica”: "Comienza negando la concepción medioeval del mundo, de la vida del Estado y de la Iglesia. Y termina afirmando una lucha social. Termina plegándose a la Revolución Francesa." ${ }^{27} \mathrm{~A}$ diferencia del Iluminismo inglés, moderado en cuestiones políticas y religiosas, entregado más bien a la investigación científica, el Iluminismo francés "se convierte (...) en el vocero intelectual de un nuevo estado social que acaba de hacer su aparición en el escenario político: el Tercer Estado, la burguesía". ${ }^{28}$ De esta manera, la problemática iluminista tiene, en Francia, varias consecuencias: se piensa que la filosofía debe contribuir al bienestar común, interviniendo en la "opinión pública", instruyendo al "pueblo" -que se identifica con la burguesía- y siendo "expresión de una espiritualidad colectiva" que se debate ingresar en la historia. ${ }^{29}$

\footnotetext{
${ }^{23}$ Ibid., pp. 1270-1271.

${ }^{24}$ Ibid., p. 1271.

25 Ibid.

${ }^{26}$ Cfr. nota 10: Cassirer, Filosofia dell'Illuminismo, p. 22.

${ }^{27}$ Guerrero, "La conciencia histórica en el siglo XVIII”, p. 1271.

${ }^{28}$ Ibid.

${ }^{29}$ Ibid., p. 1272.
} 
La nueva condición humana que emerge en el siglo XVIII, a través de "una lucha por el saber y una lucha por el poder", tiene un nombre: se llama "conciencia del hombre en su época". ${ }^{30}$ No sólo los filósofos franceses, sino también los alemanes y los ingleses, están convencidos de que la era en la cual viven tiene "una misión" y se proponen llevarla a su cumplimiento: "Por eso, de una u otra manera, asignan un sentido al pasado y trazan un camino para el futuro, siempre en función de las tareas presentes". ${ }^{31}$ Pero esta conciencia, "teórica y práctica a la vez", de la situación del hombre en su tiempo supone afrontar dos problemas: el de la "dependencia histórica" y el de "las exigencias para superar esas ataduras históricas y labrar un porvenir de mayor dignidad humana." 32 Con respecto al primero de estos problemas, el sentido histórico del Iluminismo se puede sintetizar en la célebre definición de Kant: "es el tránsito de la minoría a la mayoría de edad del género bumano." ${ }^{33} \mathrm{La}$ frase es menos una caracterización objetiva que una auto-representación, "una especie de auto-exposición de ese movimiento filosófico": los hombres del Siglo de las Luces tienen, en efecto, "la conciencia de estar viviendo en una época de tránsito, en la aurora de un nuevo día, en la crisis hacia la mayoría de edad de la vida humana". ${ }^{34}$ De ahí que sea un error decir que esta filosofía es "esencialmente anti-histórica", ${ }^{35}$ como sostuvieron los románticos en una interpretación muy difundida:

La Filosofía de la Historia es (...), para el Iluminismo, la exposición de esa nueva conciencia de la madurez humana. En términos del propio siglo XVIII, es la exposición del "progreso" de la humanidad. En este sentido podríamos decir que el concepto mismo de Iluminismo es un concepto forjado en los dominios de la Filosofía de la Historia. ${ }^{36}$

\footnotetext{
${ }^{30}$ Ibid., p. 1273.

${ }^{31}$ Ibid.

${ }^{32}$ Ibid.

${ }^{33}$ Ibid.; cfr. Immanuel Kant, "Beanwortung der Frage: Was ist die Aufklärung?" (Berlinische Monatsschrift, Nr. 4, 1784), en Gesammelte Schriften, Akademie Ausgabe, VIII, Berlin, 1923, pp. 33-42.

${ }^{34}$ Ibid., p. 1274.

${ }^{35}$ Ibid., p. 1272.

${ }^{36}$ Ibid., p. 1274.
} 
En el interior del movimiento iluminista, aduce Guerrero, pueden distinguirse tres grandes corrientes de la filosofía de la historia. En primer término, la corriente central del "progresismo culturalista", con dos subcorrientes: por un lado, "la concepción racionalista" (en parte Voltaire y Montesquieu, pero sobre todo Turgot, Condillac y Condorcet) que se remonta al siglo XVII y descansa en "una actitud vital de tipo optimista" y, por el otro, "la concepción naturalista y mecanicista" (Le Mettrie, Diderot, D'Alembert, Helvecio, Holbach), elaborada en el mismo siglo XVIII, que se funda en una actitud más bien "pesimista" de la vida humana, para la cual "la historia no está presidida por ninguna organización racional y por lo tanto tiene que moverse en un círculo de crecimiento, maduración y decadencia de los pueblos y los Estados". ${ }^{37}$ En segundo lugar, debe ubicarse la corriente opuesta del "pesimismo cultural", inaugurada por Rousseau, esto es, "la concepción de la historia como un retroceso incesante de la humanidad" ${ }^{38}$ Por último, frente a estos dos esquemas, "que operan con abstracciones pseudo-históricas y morales", se encontraría la corriente "historicista", a saber, "el intento de una adecuada valoración del pasado", que se inicia con la obra de Giambattista Vico, se cumple parcialmente en Francia con Montesquieu y alcanza su apogeo en Herder. ${ }^{39}$

La actitud peculiar del hombre moderno -o dicho de una manera más concreta, subraya Guerrero en el principio de la segunda parte de su trabajo: "del hombre de la burguesía francesa del viejo régimen en su movimiento de ascenso económico, político y social”- frente al mundo y la vida puede ser vista a la luz de tres factores, que han sido puestos de relieve por Benno von Wiese en su estudio Herder y el Romanticismo: el sentimiento ambivalente de "colaboración" de la época con la existencia personal, la secularización del tiempo y, finalmente, la crisis de la cultura moderna. ${ }^{40}$ En primer término, el sentimiento de que la época colabora positiva o negativamente con la existencia del individuo, cuyo análisis requeriría una investigación sociológica muy amplia desde sus orígenes en el Renacimiento y la

\footnotetext{
${ }^{37}$ Ibid., p.1274-1275.

${ }^{38}$ Ibid., p. 1275.

${ }^{39}$ Ibid.

${ }^{40}$ Ibid., p. 1282. El trabajo de Benno von Wiese, citado por Guerrero a pie de página, es "Kritik der eigenem Zeitalter von Herder bis zur Romantik", Die Schildgenossen, Jg. 9, Nr. 5, 1929, pp. 355-372.
} 
controversia entre la "virtud" y la "fortuna" hasta la Francia de la querelle des Anciens et des Modernes, "que inaugura propiamente el siglo XVIII y dibuja las líneas de su horizonte de preocupaciones", despierta un interés hermenéutico en la historicidad de la época. En otras palabras, "la comprensión del tiempo en un sentido histórico (...) procura aclarar los enigmas del pasado y la dirección del porvenir, para poder interpretar mejor el sentido el presente." ${ }^{41}$

Con el proceso de secularización, al que Guerrero dedica un largo excursus en el que discute las teorías de Bernhard Groethuysen en su Philosophische Anthropologie, ${ }^{42}$ la consideración de la existencia humana pasa de la pertenencia esencial a una "comunidad de destino", como en la Edad Media, donde el hombre sólo estaba en relación consigo mismo a través de Dios, al "dominio íntimo de la vida del alma". ${ }^{43} \mathrm{~A}$ partir del Renacimiento, el hombre se busca a sí mismo en su "naturaleza inmediata", en lo que experimenta "como hombre solo"; el racionalismo muy pronto transforma las "experiencias del alma" en "ideas de la conciencia" y la cuestión entera de "la interpretación de la propia vida" en "el problema de la auto-conciencia". ${ }^{44}$ En el plano de la conciencia histórica, encontramos que la historia cristiana de la salvación se ha convertido en "una Filosofía bumana y mundana de la Historia" ${ }^{45} \mathrm{El}$ seculum -ahora en el sentido moderno de la época- es aún una totalidad espacial y temporal que refleja el alma de cada individuo, pero se ha vaciado de su contenido teológico: las representaciones escatológicas sobre el Apocalipsis y el Juicio Final, que desvalorizaban el presente, como estado transitorio ante la inminente llegada de Cristo, cede ante la "conciencia temporal' moderna, que se concibe fundamentalmente como conciencia bistórica o aún más como sentido de la propia época". " ${ }^{46} \mathrm{La}$ respuesta cristiana a las viejas inquietudes sobre el destino del hombre y la sucesión de los tiempos pierden su fuerza de convicción, pero el problema permanece. El Iluminismo, con su teleologismo y su fe en el progreso, "no es una nueva concepción del mundo, sino ante todo una nueva actitud frente al mundo", subraya

\footnotetext{
${ }^{41}$ Ibid., p. 1283.

${ }^{42}$ Ibid., pp. 1284 y 1285, nota 9. Groethuysen, Philosophische Anthropologie, München und Berlin, R. Oldenbourg, 1931.

${ }^{43}$ Ibid., p. 1285.

${ }^{44}$ Ibid.

${ }^{45}$ Ibid., p. 1286.

${ }^{46}$ Ibid.
} 
Guerrero: "No es una categoría exclusivamente teórica, sino una noción práctica, una noción polémica, una categoría elaborada en los forcejeos del hombre con su propia historia." ${ }^{97}$

En los tiempos modernos, la representación escatológica del destino del género humano se ha transformado "en una dirección puramente secular y mundana". ${ }^{48}$ Con el Humanismo, los bienes y valores del cristianismo, "desprendidos del cielo, han quedado agrupados bajo la idea central de la cultura". ${ }^{49}$ Hasta mediados del siglo XVIII, esta idea es indudablemente "el concepto básico -o por lo menos la imagen de atracción mágica- de todas las preocupaciones por la historia, la sociedad y la propia época". ${ }^{50} \mathrm{Si}$ en el cristianismo la conciencia histórica había implicado "una preparación y, a la vez, en una disposición para el fin", también las supone ahora, sólo que "el fin ya no consiste en la superación del seculum por la Eternidad, sino (...) en la máxima elevación del siglo, hasta llegar a una época concebida como equivalente de la Eternidad". ${ }^{51}$ En un primer momento, esta emancipación de los fundamentos teológicos se traduce en un racionalismo optimista para el cual el sentido histórico consistiría en un progreso y perfeccionamiento de todas las capacidades humanas. Bajo esta perspectiva, el pasado aparece como "una sucesión de etapas hacia el esclarecimiento, dentro del mundo, que produce la cultura racional." 52 Pero después de este momento de optimismo -cuya finalidad de esclarecimiento o iluminación racional da al movimiento de las Luces su nombre y su programa de acción-sobreviene otro de signo inverso: un período de crisis, representado por Rousseau, que en su Discours sur les sciences et les arts, escrito en 1750, denuncia que el desarrollo de la cultura sólo enmascara la corrupción de las costumbres y la decadencia moral.

En las teorías contra-ilustradas de Rousseau, más claramente que en ningún otro autor de la época, se expresan las "antinomias de la conciencia histórica” del siglo XVIII que Guerrero examina en la tercera sección de

\footnotetext{
${ }^{47}$ Ibid.

${ }^{48}$ Ibid., p. 1287.

${ }^{49}$ Ibid., p. 1288.

${ }^{50}$ Ibid., p. 1289.

${ }^{51}$ Ibid.

${ }^{52}$ Ibid.
} 
su trabajo. ${ }^{53} \mathrm{El}$ filósofo ginebrino procede a un "trastocamiento de todos los valores culturales realizados en la historia" y, en su condena radical del progreso, "llega a la negación de la historia". ${ }^{54}$ En efecto, frente a la historia iluminista, concebida como un desarrollo progresivo a través de una sucesión de etapas culturales, Rousseau postula "un estado extra-histórico, un estado que concibe como naturaleza" ${ }^{55}$ Sin embargo, en Émile y en Julie, pero sobre todo en $D u$ Contrat social, no queda prisionero de "este antagonismo entre el estado de naturaleza y el régimen de cultura", entre las demandas de una libertad originaria y las formas inauténticas de la organización social, sino que busca resolverlo dentro de la propia dinámica histórica, integrando "la libertad en el orden": el "contrato social" será la síntesis de "la vida natural espontánea" y "la vida histórica opresora", del amour de soi y la volonté de nous, capaz de elevar la libre auto-enajenación del individuo en la volonté génerale a "principio de la convivencia humana". ${ }^{56}$

Pero la riqueza de esta dialéctica no sería apreciada por sus contemporáneos: frente a la tesis del progresismo cultural, que ha de prolongarse en el liberalismo pre y post-revolucionario, la obra de Rousseau se presenta como "una antitesis escurridiza", dotada de una inquietante "duplicidad". ${ }^{57}$ Una antinomia ciertamente persiste en la filosofía social del iluminismo: el hombre que "produce" los bienes culturales, las costumbres y las instituciones y el hombre que "los comprende, que lo llena de racionalidad", en el sentido de Max Weber, no es el mismo. ${ }^{58}$ Mientras que todas estos fenó-

${ }^{53}$ Ibid., p. 1290.
${ }^{54}$ Ibid..
${ }^{55}$ Ibid., p. 1291.
${ }^{56}$ Ibid.; cfr. Jean-Jacques Rousseau, Du contrat social ou Principes du Droit politique, en Euvres complètes, tome III : Du Contrat social. Écrits politiques, édition publiée sous la direction de Bernard Gagnebin et Marcel Raymond, Paris, Gallimard: Bibliothèque de la Pléiade, 1964, Livre I, Chapitre VI, pp. 360-362 y Livre II, Chapitre III y Chapitre IV, pp. 371-375.

${ }^{57}$ Ibid.

${ }^{58}$ Ibid., p. 1292. Guerrero no menciona ninguna obra de Max Weber en este texto, ni en ninguno de los programas de los cursos dictados en la UBA y la UNLP. La referencia muy probablemente proceda de la exposición que sobre su interpretación del mundo de la burguesía capitalista en términos de "racionalización" ofrecía Löwith en el trabajo publicado en el Archiv für Sozialwissenschaft und Sozialpolitik de 1932, al que hemos aludido más arriba (cfr. nota 4). Sobre las lecturas argentinas de 
menos constituyen "la expresión de una comunidad histórica", "el hombre que los valora y conoce, el hombre de la sociedad burguesa es, fundamentalmente, un individuo particular". ${ }^{59}$ En otras palabras, el siglo XVIII "pretende comprender el mundo histórico-social en tanto es un producto de la actividad humana en general, pero para ello sólo se dispone de "una conciencia individual, aislada, robinsoniana". ${ }^{60} \mathrm{En}$ el Iluminismo, el sujeto únicamente afirma como tal "en la receptividad del conocimiento"; en el orden de los acontecimientos, en cambio, aún se concibe como res extensa: "las objetivaciones histórico-sociales son asimiladas a las estructuras de la naturaleza, es decir que son explicadas como si fueran entes extraños a la vida humana". ${ }^{61}$

Junto a esta antinomia, otra quizás más poderosa se despliega en el dominio del pensamiento iluminista de la historia, donde también Rousseau "expresa la antitesis frente a la tesis del progresismo liberal": por un lado, el desarrollo de las artes y las ciencias hace concebir ilusiones en el provenir del género humano; por el otro, el mito del "buen salvaje" arroja sobre el presente la sombra perturbadora de una humanidad pre-histórica, "inocente y feliz precisamente porque no conoció la civilización". ${ }^{2}$ Ambas posiciones entrañan "una negación de la historia o cuanto menos una valoración negativa" de la herencia cultural: sobre la tabula rasa de las tradiciones históricas, fuente de miserias y supersticiones, la primera proyecta "la idea del Reino de la Razón"; ${ }^{33}$ la segunda “opone la naturaleza - en el sentido de Rousseau- a la

Weber que ofrecían por entonces Raúl Orgaz, Alfredo Poviña e Ignacio Treves y la incorporación de sus obras a los programas de enseñanza como parte de la reacción a la sociología positivista predominante hasta las primeras décadas del siglo XX, cfr. Alejandro Blanco, "La temprana recepción de Max Weber en la sociología argentina (1930-1950)", Perfiles Latinoamericanos, n 30, Facultad Latinoamericana de Ciencias Sociales, México, julio-diciembre 2007, pp. 9-38.

${ }^{59}$ Ibid.

${ }^{60}$ Ibid.

${ }^{61}$ Ibid., p. 1293. Como excepción, Guerrero cita el párrafo de una carta de Diderot, donde "no encontramos la naturaleza como el tema sentimental de los rousseaunianos, ni como el conjunto de abstracciones físico-matemáticas de las ciencias naturales, sino como un ingrediente fundamental del mundo circundante humano". Cfr. Denis Diderot, Correspondance, éditée par Georges Roth et Jean Varloot, 16 volumes, Paris, Minuit, 1955-1970, t. XIII, p. 90.

${ }^{62}$ Ibid., 1294.

${ }^{63}$ Ibid., p. 1295. 
historia", concebida como portadora de "una decadencia de las fuerzas primitivas, esencialmente nobles, del hombre". ${ }^{64}$ Haciendo suya la crítica rousseauniana de la cultura, que había dado "un doble sentido a la conciencia de la época", la Revolución francesa pretenderá combinarlas, esto es, querrá "renovar" el estado de naturaleza, "traerlo a nueva vida", "cumplirlo, de una vez para siempre, convirtiéndolo en el estado final" de la civilización:

Ésta es la conciencia histórica dominante en la Revolución francesa. Es una conciencia histórica que, por una parte, niega a la época. Niega al siglo, en tanto ese siglo depende del pasado histórico. Pero, al mismo tiempo, lo renueva escatológicamente por medio de una voluntad, sea de orden racionalista o de carácter naturalista. Y así afirma a la época en una medida superior.

El Juicio Final se cumple ahora dentro del mundo. Se cumple por medio de un conocimiento racional verdadero, dirán los racionalistas. Por medio de un sentimiento natural que es certidumbre y salvación a la vez, dirán los partidarios de Rousseau.

Así la propia época no es solamente el punto final de un proceso histórico, sino, también, el punto inicial de un movimiento de liberación, que se puede alcanzar $(\ldots)$ por fuerzas racionales o por fuerzas naturales. ${ }^{65}$

Así resume Guerrero, en la sección final del trabajo, su principal argumento sobre el problema de la conciencia histórica en la Revolución francesa. Ésta ha extraído sus energías de las antinomias propias del Siglo de las Luces. Naturaleza y razón ya no se oponen entre sí, sino que constituyen "dos realidades, dotadas por igual de un sentido utópico que el pensamiento revolucionario opone a la historia". ${ }^{66} \mathrm{Si}$ la actitud de los hombres de 1789 puede calificarse de "anti-histórica", lo es en virtud de esta búsqueda de "una realidad superior a la historia, que se ha de encontrar (...) o en los senos primigenios de la naturaleza o en el Reino libre de la Razón", ${ }^{67}$ cuando no en la unidad de ambos, en un estadio donde el origen y la meta de la humanidad, su pre y post-historia, finalmente convergen. La realización del porvenir demanda, sin embargo, vivir el presente de la manera más intensa, asumir lo que se

\footnotetext{
${ }^{64}$ Ibid., p. 1296.

${ }^{65}$ Ibid., p. 1297.

${ }^{66}$ Ibid.

${ }^{67}$ Ibid., p. 1297-1288.
} 
interpreta como "destino histórico" y llevar a cumplimiento, en consecuencia, "el sentido de la época". ${ }^{68}$ Así, alega Guerrero, el programa político-social de la Revolución francesa "adquiere, a pesar suyo, una dimensión histórica que se convierte en el preludio de la conciencia profundamente histórica que ha de caracterizar a todos los grandes movimientos del siglo XIX, tanto en el terreno de las ideas como en el de los hechos". ${ }^{69}$

Ahora bien, en los albores del siglo XIX, este pensamiento choca con el "historicismo tradicionalista", conservador y a veces reaccionario de los románticos, con "su actitud de sumisión y veneración" frente al pasado y su adhesión al movimiento de la Restauración. ${ }^{70}$ Así como defiende los valores de la tradición y combate, en su nombre, "el afán iconoclasta" de la generación revolucionaria", el Romanticismo polemiza también contra la "concepción mecanicista y atomista del Iluminismo", a la que opone "una concepción organicista del mundo, de la vida, del hombre y de la sociedad", como ha señalado Hans Freyer en un estudio sobre la sociología romántica. ${ }^{71}$ Esa totalidad orgánica es "unas veces el Estado, otras la sociedad y, más frecuentemente, el pueblo". ${ }^{72}$ Tras las huellas de Edmund Burke y Joseph de Maistre, los románticos alemanes -de Johann Gottlieb Fichte y Friedrich Schlegel a Adam Müller- conciben los pueblos como entidades histórico-naturales, como "grandes organismos espirituales", como "reservas de productividad humana", dice Freyer: "son los actores que operan en la historia" creando las artes y las lenguas, las costumbres y las leyes. ${ }^{73} \mathrm{De}$ esta manera, afirmando que "toda realidad social y cultural es esencialmente histórica", este organicismo acaba volviéndose historicista. Pero el Romanticismo, a la vez que historiza la naturaleza, naturaliza la historia, interpretándola como un proceso que debe seguir las etapas inherentes a una evolución biológica, que ninguna fuerza externa puede alterar. En esta analogía se basa su rechazo del voluntarismo jacobino y de la Revolución Francesa

\footnotetext{
${ }^{68}$ Ibid., p. 1298.

${ }^{69}$ Ibid.

${ }^{70}$ Ibid., p. 1299.

${ }^{71}$ Ibid.; cfr. Hans Freyer, "Die Romantiker", en Fritz Karl Mann (Hg.), Gründer der Soziologie (= Sozialwissenschaftliche Bausteine, Band IV) Jena, G. Fischer, 1932, [pp. 79-95] p. 83.

${ }^{72}$ Ibid.

${ }^{73}$ Ibid.; Freyer, "Die Romantiker", p. 86. La traducción y el subrayado pertenecen a Guerrero.
} 
en su conjunto, a la que considera "esencialmente anti-histórica, porque ha pretendido acelerar y aun modificar el desarrollo paciente de las cosas". ${ }^{74}$

Esta digresión sobre el Romanticismo permite definir la problemática específica del pensamiento de la Revolución Francesa y su herencia en los movimientos sociales del siglo XIX como "la antitesis entre la conciencia histórica y la conciencia revolucionaría" ${ }^{75}$ Rodolfo Mondolfo, subraya Guerrero, "ha expuesto, de una manera especialmente lúcida, los términos en que se planteó esta cuestión a fines del siglo XVIII". ${ }^{76}$ En efecto, el filósofo italiano, que acababa de llegar a la Argentina escapando del fascismo, había desarrollado el tema en una conferencia pública, que repetiría dos años después en la ciudad de San Miguel de Tucumán y acabaría publicando en la revista Sustancia, dirigida por Alfredo Coviello, con el título "La antinomia del espíritu innovador". ${ }^{77}$ Guerrero sigue de cerca el análisis de Mondolfo, para

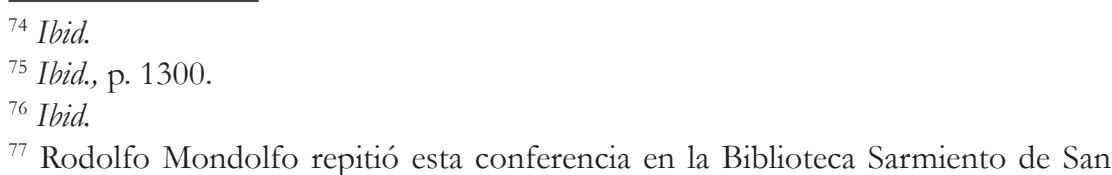
Miguel de Tucumán el 30 de septiembre de 1941: "La antinomia del espíritu innovador", Sustancia. Revista de cultura superior, no 9, [San Miguel de] Tucumán, Sociedad Sarmiento/Grupo Septentrión, abril 1942, pp. 12-31. Se encontrará un desarrollo complementario del tema en "Espíritu revolucionario y conciencia histórica", Revista mexicana de sociología, vol. 3, n 4, octubre-diciembre 1941, pp. 71-86 y Boletín del Instituto de Sociología, Universidad de Buenos Aires, n 1, 1942, pp. 43-55. Ambos textos fueron recopilados en Espíritu revolucionario y conciencia histórica: ensayos críticos de sociología e historia de las ideas (Buenos Aires, Ediciones Populares Argentinas, 1955), el primero de ellos con el título "La antinomia del espíritu revolucionario". Tras ser expulsado de su cátedra en la Universidad de Bologna, Mondolfo se exilió en la Argentina con su esposa y sus tres hijos a principios de mayo de 1939, gracias a una invitación de Coriolano Alberini, Decano de la Facultad de Filosofía y Letras de la UBA y las gestiones de M. H. Alberti, que había traducido Fenerbach y Marx. La dialéctica y el concepto marxista de la historia (Buenos Aires, Claridad, 1936), y de Alfredo L. Palacios, miembro del Partido Socialista. Durante los primeros meses en el país, desarrolló una intensa actividad como conferencista. En la sede del CLES impartió, en agosto de 1939, una conferencia sobre Tomasso Campanella y, entre septiembre y octubre, el seminario "La teoría del conocimiento en la historia de la filosofía”, que comprendió los temas siguientes: “1) La antigüedad; 2) La filosofía cristiana; 3) La filosofía moderna; 4) Kant y el criticismo; 5) Positivismo y evolucionismo”. Cfr. Diego Pró, Rodolfo Mondolfo, 2 vols., Buenos Aires, Editorial 
quien la filosofía de la Revolución francesa "afirma la exigencia de un nuevo mundo social creado por la fuerza de la razón o la inspiración de la naturaleza, y condena como irracional e innatural el régimen producido por la historia." 78 Precisamente esta voluntad de ruptura de la "continuidad histórica", comenta, es la que surge con el mayor vigor en la mentalidad revolucionaria de los hombres de 1789: el presente se concibe como una línea divisoria y la idea de progreso, que parecía ser "la explicación histórica más adecuada" para el Iluminismo, por tanto "queda al margen de la actividad revolucionaria". ${ }^{79}$

Con el correr del tiempo, los movimientos políticos y sociales que se reclamaron herederos de la Revolución francesa adquirieron, por contraste, "un sentido profundamente histórico", señala Guerrero. ${ }^{80}$ La diferencia entre la "posición negativa" frente a la historia de los revolucionarios de 1789 y la "posición afirmativa" de los del siglo XIX debe buscarse en las diferentes condiciones históricas de ambas épocas. La burguesía ascendente de los tiempos del Iluminismo no sentía ninguna "comunidad de intereses" con el régimen feudal decadente, que identificaba con "el mal y el pasado, en oposición al Tercer Estado, que representaba para ella "el bien y el futuro". ${ }^{81}$ Pero esto cambia con el surgimiento del socialismo, el comunismo y el anarquismo; el proletariado descubre, entonces, que "el desarrollo de la burguesía le resulta indispensable, porque condiciona el propio desarrollo de la clase obrera", que "la clase dominante cumple históricamente una función útil para la clase dominada". ${ }^{82}$ Por tanto, no puede decirse que la mentalidad revolucionaria sea "necesariamente anti-histórica"; sólo adopta esta tesitura "cuando se acentúan -como en el siglo XVIII- las oposiciones entre el pasado y el futuro, entre lo real y lo ideal (...)". ${ }^{83}$ En 1789, mientras la conciencia revolucionaria "acentuaba el valor del futuro como una creación espontánea del hombre", la conciencia histórica, en cambio, ponía el

Losada, 1967, vol. 1, pp. 35-36 y Colegio Libre de Estudios Superiores, Quince años de labor, p. 55.

${ }^{78}$ Mondolfo, Espíritu revolucionario y conciencia bistórica, p. 36.

${ }^{79}$ Guerrero, "La conciencia histórica en el siglo XVIII", p. 1301.

${ }^{80}$ Ibid.

${ }^{81}$ Ibid.

${ }^{82}$ Ibid.

${ }^{83}$ Ibid. 
énfasis en el valor del pasado hasta volverse gradualmente "contrarrevolucionaria", como de hecho ocurrió en tiempos de la Restauración. ${ }^{84}$

En efecto, la antítesis entre la conciencia revolucionaria y la conciencia histórica -que encuentra en la Revolución francesa su formulación más clásica- "aparece en el momento de la acción", afirma Guerrero, recordando los términos en que Mondolfo ha planteado la cuestión: "surge (...) de la doble necesidad de concebir nuestra dependencia y, a la vez, nuestra independencia con respecto al pasado histórico" y se configura, por eso mismo, como "una antinomia entre el reconocimiento y el repudio (...) de los valores de la historia". ${ }^{85}$ Según Mondolfo, esta antinomia resulta determinada por una doble intuición: por un lado, la historia es tomada como una "interioridad" viviente, parte constitutiva del propio espíritu, que se experimenta como creador de ella; por el otro, como una "exterioridad", que intenta limitarlo, sofocarlo "bajo su peso muerto" ${ }^{86}$ Guerrero entiende que, en el pensamiento de 1789, hay una tendencia a transformar este contraste entre lo real y lo ideal en "una oposición entre lo interior -el espíritu, esa fuente perenne de libertad de que nos habla Rousseau-y lo exterior, esa dominación de las tradiciones históricas y sociales". ${ }^{87}$ Pero esta "exteriorización" de la historia, esta "enajenación", tiene lugar cuando el ser humano "se coloca frente a las objetivaciones de su propia actividad" como si fueran "obras ajenas", esto es, cuando los productos de la cultura, sustraídos al mundo de la praxis, "se presentan ante su conciencia" como si fueran cosas que "contempla de una manera objetiva" y llega a concebir como "productos naturales". 88

Esta situación, subraya Guerrero, es la "premisa existencial de la interpretación burguesa de la historia": luego de haberse emancipado de las representaciones cristianas, el hombre del Siglo de las Luces las engloba "bajo el concepto de cultura", tomándolas como realizaciones objetivas que concibe "siempre por analogía con el mundo exterior". ${ }^{89}$ El burgués "domina" la naturaleza por el trabajo y la técnica en la medida que la conoce, pero se siente atado a ella por las mismas leyes con las que la explica. Algo

\footnotetext{
${ }^{84}$ Ibid., pp. 1301-1302.

${ }^{85}$ Ibid., p. 1302; Mondolfo, Espiritu revolucionario y conciencia histórica, p. 50.

${ }^{86}$ Ibid.

${ }^{87}$ Ibid,

${ }^{88}$ Ibid.

${ }^{89}$ Ibid., pp. 1302-1303.
} 
similar le ocurre con el mundo histórico-social: si bien reconoce su origen humano, piensa que escapa a su actividad individual y, con el propósito de entenderlo, "elabora leyes histórico-sociales a semejanza de las leyes naturales". ${ }^{90}$ De ahí que pueda decirse que "el horizonte de comprensión histórica para la mentalidad burguesa del siglo XVIII, y para sus herederos hasta la actualidad, se encuentra en la estructura general de la naturaleza", a saber, "en la producción natural de los acontecimientos histórico-sociales". ${ }^{91}$ Por este motivo, los iluministas, Rousseau, los fisiócratas y los ideólogos de 1789 conciben de uno u otro modo la acción humana en la historia como una restitución del orden natural oscurecido o perdido.

Esta concepción anti-histórica es lo que caracteriza el pensamiento de la Revolución Francesa, a diferencia de los movimientos sociales y políticos que surgieron durante el siglo XIX, en los cuales la conciencia histórica ya no se opone, sino que se identifica con la conciencia revolucionaria. "La mentalidad de la época no se hace cargo de una circunstancia tan simple, pero decisiva, como la siguiente: que el hombre, al tomar conciencia de la realidad histórico-social, ya la cuestiona. Y que al cuestionarla, ya la transforma", concluye Guerrero, reescribiendo el dictum de Marx y Engels. ${ }^{92}$ La lección que precisamente ha aprendido el espíritu revolucionario es que la teoría y la praxis se esclarecen recíprocamente, que interpretar y querer cambiar el mundo, comprender y actuar sobre la realidad, no son tareas excluyentes, sino complementarias entre sí:

En otros términos, que el hombre sólo hace historia en tanto la comprende -en tanto tiene un trato vidente con los sucesos históricos-, como inversamente, sólo comprende la realidad histórico-social en tanto actúa sobre ella. Su decisión de conocer la historia sólo puede existir en su voluntad de intervenir en la bistoria. Por eso su interpretación de la historia ha de coincidir siempre con la dirección de la propia vida. ${ }^{93}$

Recibido 2/2014; aceptado: 4/2014

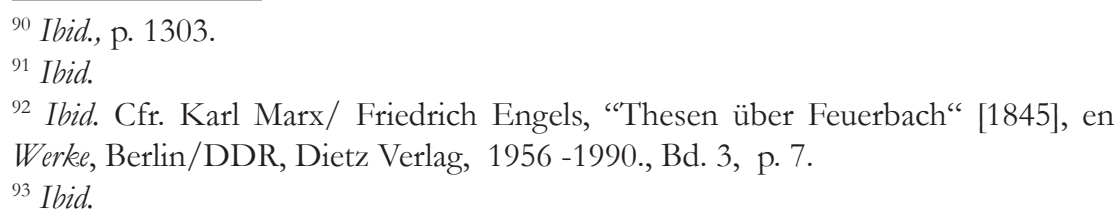


